\title{
BMJ Open Implementation of care managers for patients with depression: a cross- sectional study in Swedish primary care
}

\author{
Pia Augustsson (1D ,1,2 Anna Holst, , ${ }^{1,2}$ Irene Svenningsson,, ${ }^{1,2}$ Eva-Lisa Petersson, ${ }^{1,2}$ \\ Cecilia Björkelund (D) , 1,2 Elisabeth Björk Brämberg (iD) 1,2,3
}

To cite: Augustsson $P$, Holst A, Svenningsson I, et al. Implementation of care managers for patients with depression: a crosssectional study in Swedish primary care. BMJ Open 2020;10:e035629. doi:10.1136/ bmjopen-2019-035629

- Prepublication history and additional material for this paper are available online. To view these files, please visit the journal online (http://dx.doi. org/10.1136/bmjopen-2019035629).

Received 08 November 2019 Revised 03 March 2020 Accepted 06 April 2020

\section{Check for updates}

\section{(c) Author(s) (or their} employer(s)) 2020. Re-use permitted under CC BY-NC. No commercial re-use. See rights and permissions. Published by BMJ.

${ }^{1}$ Primary Health Care, School of Public Health and Community Medicine, Institute of Medicine, Sahlgrenska Academy, University of Gothenburg, Gothenburg, Sweden

${ }^{2}$ Research and Development, Primary Health Care, Region Västra Götaland, Sweden ${ }^{3}$ Institute of Environmental Medicine, Karolinska Institutet, Stockholm, Sweden

Correspondence to Pia Augustsson; pia.augustsson_olsson@ vgregion.se

\section{ABSTRACT}

Objectives To perform an analysis of collaborative care with a care manager implementation in a primary healthcare setting. The study has a twofold aim: (1) to examine clinicians' and directors' perceptions of implementing collaborative care with a care manager for patients with depression at the primary care centre (PCC), and (2) to identify barriers and facilitators that influenced this implementation.

Design A cross-sectional study was performed in 20162017 in parallel with a cluster-randomised controlled trial. Setting 36 PCCs in south-west Sweden.

Participants PCCs' directors and clinicians.

Outcome Data regarding the study's aims were collected by two web-based questionnaires (directors, clinicians). Descriptive statistics and qualitative content analysis were used for analysis.

Results Among the 36 PCCs, 461 (59\%) clinicians and $36(100 \%)$ directors participated. Fifty-two per cent of clinicians could cooperate with the care manager without problems. Forty per cent regarded to their knowledge of the care manager assignment as insufficient. Around twothirds perceived that collaborating with the care manager was part of their duty as PCC staff. Almost $90 \%$ of the PCCs' directors considered that the assignment of the care manager was clearly designed, around $70 \%$ considered the priority of the implementation to be high and around $90 \%$ were positive to the implementation. Facilitators consisted of support from colleagues and directors, cooperative skills and positive attitudes. Barriers were high workload, shortage of staff and extensive requirements and demands from healthcare management.

Conclusions Our study confirms that the care manager puts collaborative care into practice. Facilitators and barriers of the implementation, such as time, information, soft values and attitudes, financial structure need to be considered when implementing care managers at PCCs.

\section{INTRODUCTION}

Mental health problems are a serious burden for patients and healthcare systems worldwide. ${ }^{12}$ Depression affects $10 \%-15 \%$ of the population $^{34}$ and up to $70 \%$ of patients with common mental disorder (CMD), that is, mild to moderate depression, anxiety, adjustment and stress-related disorders, are diagnosed and treated in primary care. ${ }^{5}$

\section{Strengths and limitations of this study}

A strategic sampling of primary care centres (PCCs) with regard to geographical location, funding and PCC size revealed a variation in clinicians' and directors' perceptions.

- The response rate was outstanding for the PCC directors.

- The results' generalisability to international primary care contexts is partly limited, as the Swedish primary care organisation differs from other countries.

- A majority of the items used in the clinician's questionnaire have been tested with regards to their reliability.

Collaborative care interventions, that is, organisational interventions aimed at providing high-quality patient care by the support of leadership and decision support within the primary care centre (PCC), and access to psychiatry have shown to be effective in reducing sickness absence. ${ }^{6}$ However, the evidence in the area is relatively limited, and it is uncertain whether previous studies actually stress the importance of collaborative care and care management. ${ }^{7}$ On the other hand, previous studies have shown that single interventions (eg, waiting room screening, development of guidelines) do not result in improved treatment and management of depression when delivered in primary care. ${ }^{89}$ Collaborative care, with a care manager, is an integrated team-based primary care intervention that seeks to support and enhance interprofessional communication and uses structured care planning. ${ }^{10}$ The care manager has two types of functions: (1) to increase accessibility and continuity of care for the patient at the PCC via patient contacts, ${ }^{11}$ and (2) educational development at the PCC to improve communication and feedback within the PCC team and communication with secondary care. ${ }^{811-13}$ 
The Swedish Council on Health Technology Assessment has called for studies on collaborative care organisation with a care manager conducted in Swedish primary care, ${ }^{14}$ as complex interventions behave differently depending on the context. ${ }^{1516}$ Consequently, a pragmatic cluster-randomised controlled trial (PRIM-CARE) was performed in Swedish primary care, comparing effects of care managing versus care as usual (CAU) for depression at PCCs during 2014 to $2016 .{ }^{8}$ The care managers participating in the PRIM-CARE trial received a 3-day training. During the first year after this training, the care manager had access to four 1-day booster sessions. PCCs had continuous support, regarding implementation and method, from both the research team and the region's implementation team, with frequency dependent on need. The care manager's specific role was to first meet with the patient in face-to-face meetings, develop an individual care plan, perform telephone follow-ups on a regular basis (6-8 times during 12 weeks), inform about depression and provide behavioural education and self-care advice. The care manager was to stay in regular touch with the patient's general practitioner (GP). A detailed description of the care manager's training, specific roles and duties and so on is given elsewhere. ${ }^{8}$ The results showed positive effects on depression course with less symptoms, reduced remission frequency, adequate antidepressant medication, increased quality of life and fewer costs from a societal perspective compared with CAU. ${ }^{89}$ In addition the intervention was valued by the patients. ${ }^{17-19}$

However, staff and organisational factors are known to be decisive for whether an implementation will succeed or not. ${ }^{20}$ According to previous studies, facilitators for implementing collaborative care for depression in primary care are strong leadership, standardised systematic clinical pathways, sufficient training and regular supervision for staff, ${ }^{10} 12$ on-site and accessible care managers, ${ }^{11}{ }^{21}$ as well as social and professional skills of the care managers. ${ }^{22}$ Existing service structures, unfavourable financial structures, ${ }^{10} 21$ lack of organisational, administrative and professional ability to change and implement and lack of clarity of the responsibility of the care manager ${ }^{23} 24$ are identified as barriers. In order to further develop and adjust the care manager function to the primary healthcare setting, the present study aims to (1) examine the clinicians' and directors' perceptions of implementing collaborative care with a care manager for patients with depression at the PCC, and (2) identify barriers and facilitator, that influenced this implementation.

\section{METHOD}

\section{Design and setting}

The study used a cross-sectional survey design. Data were collected by questionnaires directed to clinicians and directors within primary healthcare.

\section{Study population}

In July 2016, 200 PCCs were operating in Region Västra Götaland, of which 83 had an established care manager. A strategic sampling at the PCC level made it possible to invite 39 PCCs and still provide a manageable and representative number of participants based on geographical and organisational differences.

The first step in the strategic sampling was a geographical division, the second was a subdivision into city, urban or rural, and the final subdivision was between privately or publicly run PCCs in each area. Figure 1 illustrates the sampling procedure.

Two groups of participants were invited to participate: clinicians (of any profession including administrative personnel) and directors of the PCCs included from the strategic sampling. The PCCs' care managers and the eight PCCs that participated in the pilot study were not invited to participate.

\section{The questionnaires}

Two different questionnaires were used, that is, one directed to the clinicians and another one directed to the directors of the PCCs. The purpose of using different questionnaires for the two groups was to capture different experiences that might have occurred according to different roles in the collaborative care organisation as well as in the implementation process of the PCC care manager.

The first part of both questionnaires consisted of questions about background characteristics, that is, gender, age, profession and name and funding of the PCC (private or public).

The statements in the second part were developed from questionnaires used in previous studies evaluating

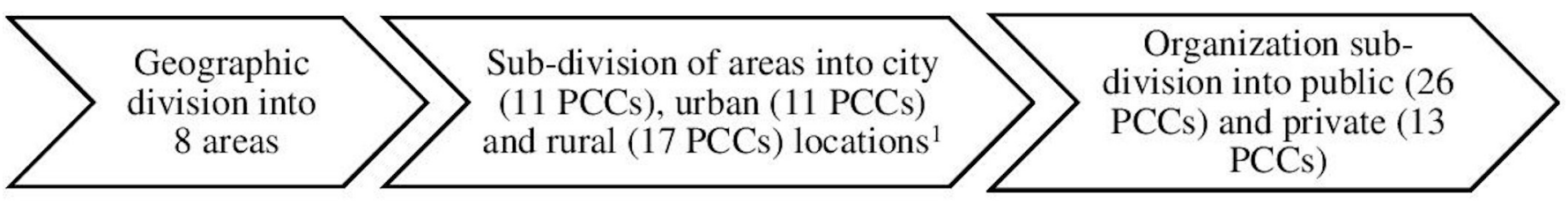

\section{'Definitions: City location: $>100000$ residents, Urban location: Town with $>200$ residents, Rural location: area with villages $<200$ residents}

Figure 1 Sampling procedure mono images. ${ }^{1}$ Definitions: City location: $>100000$ residents, urban location: town with $>200$ residents and rural location: area with villages $<200$ residents. PCCs, primary care centres. 
the Swedish rehabilitation guarantee. These studies were conducted in the same context as the present study. ${ }^{202526}$ Additional questions were related to the Consolidated Framework for Implementation Research guide (http:// www.cfirguide.org). ${ }^{27} 28$

The questionnaires were pilot tested at eight PCCs preceding the full-scale data collection. The types of settings in which the pilot was conducted varied as follows: geographic, that is, two PCCs located in a city, four PCCs with rural location and two PCCs with urban location (city location: $>100000$ residents, urban location: town with $>200$ residents, rural location: area with villages $<200$ residents $^{29}$ ); PCC size, ie, $<24$ employees and $\geq 24$ employees four PCCs each. The directors and participants who took part in the pilot test were not invited to participate in the full-scale study. After the pilot test, a few modifications were made. In both questionnaires the structured responses regarding the profession were changed to reflect prevalent PCC professions. The questionnaire for the clinicians was modified regarding two items. 'Facilitating reasons in my work with the care manager' and 'hindering reasons in my work with the care manager' were changed to 'Facilitating factors in my work with the care manager' and 'hindering factors in my work with the care manager'.

\section{The questionnaire to clinicians}

The web-based questionnaire consisted of 34 items. The first part consisted of 4 background questions and the second part had 30 statements addressing factors for the care manager implementation as well as statements addressing facilitators and barriers for cooperation with the care manager. Two statements referred to depression and anxiety, where anxiety was considered as part of symptoms of the depression. Three open-ended questions were included. See online supplementary appendix 1 (Questionnaire to clinicians).

\section{The questionnaires to PCC directors}

The web-based questionnaire consisted of 15 items: 4 background characteristics and 11 items addressing the care manager implementation. In addition, three openended questions were included. See online supplementary appendix 2 (Questionnaire to PCC directors).

\section{Data collection}

The PCC directors' email addresses were collected from the Primary Healthcare Head Office, via the PCCs' websites and the primary healthcare's research and development unit. In May 2016, a request was sent by email to the directors of the PCCs included. The email also included information about the study and a request for the email addresses of the clinicians at the PCC. From November through December 2016, the clinicians and directors were sent a personal email with a link to the questionnaire, administrated by esMaker (https://entergate.se/products/esmaker/), as well as a cover letter concerning the study, with information about the study purpose and terms of participation.

The data from the two questionnaires were gathered over a period from November 2016 through April 2017. During this time six reminders were sent by email, initially at 2-week intervals and towards the end of the period at 4-week intervals. Also, at the PCCs where the response rate was $<50 \%$, the PCC directors were asked (by email and/ or phone) to remind their clinicians. On completion of the electronic survey, all participants were offered a token (Lottery ticket $3 £$ ) for their participation by email. The token was sent out when the survey was closed.

\section{Statistical analysis}

Data analysis was performed with statistical software SPSS V. 25.0. Descriptive statistics were used to present the demographic characteristics of the participants, separately for directors and clinicians.

For data analysis, the answer options with scale 1-5 were categorised as a three-point scale, that is, 1-2, 3, 4-5, and those with scale $1-4$ were dichotomised as a two-point scale, that is, 1-2, 3-4.

Descriptive statistics of the items, for directors and clinicians separately, were compiled for the following groups:

1. The study population as a whole

2. The treating and administrative professionals, respectively (for the clinicians' result only).

3. The staff working at small and large PCC units, respectively.

4. The staff working at city, urban and rural PCC units, respectively.

Frequencies were compared by using $\chi^{2}$, all two-sided, tests. Statistical significance was set at $p<0.01$ to make the significance test more stringent ${ }^{30}$ and to reduce risk of mass significance because of high number of comparisons.

\section{Qualitative analysis}

The open-ended questions were analysed inductively by means of manifest content analysis according to Graneheim et al. ${ }^{31} 32$

The free text answers within each question area were compiled separately for the PCC directors and the PCC clinicians. The free text answers were read through several times, and with the objective in focus, meaning units were identified. The meaning units were compared with each other, abstracted and labelled with codes. The codes were compared with each other based on differences and similarities and grouped into categories with subcategories representing similar meanings, which constituted the manifest content. ${ }^{31} 32$

Data analysis was performed by PA. In order to strengthen the trustworthiness, codes, categories and subcategories were discussed in the research team, whose members represented a counsellor (PA), registered nurses (IS, EBB), occupational therapist (ELP), GPs (CB, $\mathrm{AH})$ and a director of a PCC (AH) in the primary healthcare sector. 


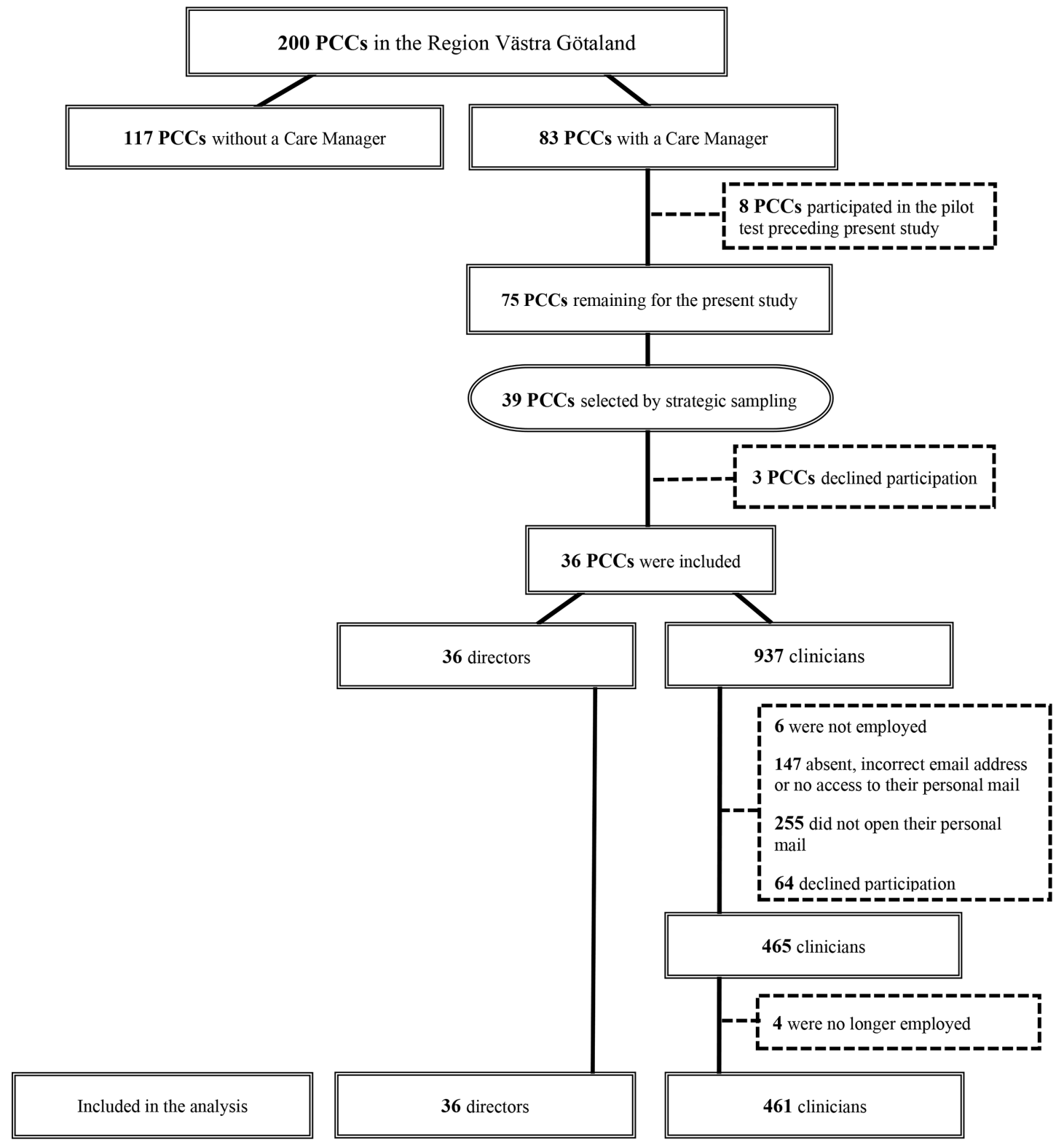

Figure 2 Flowchart including procedure mono images. PCCs, primary care centres.

\section{Patient and public involvement}

Neither patient nor public involvement was incorporated in the design and conception of the study.

\section{RESULTS}

Of the invited 39 PCCs, 3 declined participation due to workload. Figure 2 shows the inclusion procedure of the PCCs. A total of $461(56 \%)$ clinicians participated by answering the questionnaire which came with information by email, and were included in the analysis. The email including the PCC directors' questionnaire reached 36 directors and all of them gave their consent to participation by submitting the questionnaire, which yielded a total of 36 directors included in the analysis (100\%).

For both groups (clinicians and directors), $50 \%$ of the respondents were in the age range of 31-50 years, $86 \%$ were female and $70 \%-75 \%$ had a public employer.
The most common profession in both groups was nurse followed by physician. The most frequent size of PCC was $>24$ employees and the most frequent geographical location was urban (see table 1).

\section{Quantitative results}

Clinicians' perceptions of the care manager implementation

Around $40 \%$ perceived that the efforts of the care manager increased accessibility to the PCC for patients with depression, while $46 \%$ neither agreed nor disagreed that the care manager's efforts increased continuity for the patient group. There were no clear results regarding whether a care manager represented a change in their work with patient treatment.

Approximately half $(51 \%)$ perceived that their patients were generally positive to the care manager's efforts. Furthermore, $70 \%$ perceived that their duty as a staff member was to collaborate with the care manager, while 
Table 1 Background characteristics of the study population

\begin{tabular}{|c|c|c|}
\hline & $\begin{array}{l}\text { Clinicians, } \\
n=461\end{array}$ & $\begin{array}{l}\text { Directors, } \\
\mathrm{n}=36\end{array}$ \\
\hline Gender & $n=444$ & $\mathrm{n}=36$ \\
\hline Female, n (\%) & $380(85.6)$ & $31(86.1)$ \\
\hline Male, n (\%) & $64(14.4)$ & 5 (13.9) \\
\hline Age & $n=452$ & $\mathrm{n}=36$ \\
\hline 20-30, n (\%) & $32(7.1)$ & - \\
\hline $31-50, \mathrm{n}(\%)$ & $228(50.4)$ & $18(50)$ \\
\hline$\geq 51, \mathrm{n}(\%)$ & $192(42.5)$ & $18(50)$ \\
\hline Employer & $\mathrm{n}=445$ & $\mathrm{n}=36$ \\
\hline Public, n (\%) & $318(71.5)$ & $23(64)$ \\
\hline Private, n (\%) & $127(28.5)$ & $13(36)$ \\
\hline Employment & $n=449$ & $n=36$ \\
\hline Care providing ${ }^{\star}, \mathrm{n}(\%)$ & 401 (89.3) & - \\
\hline Administrative†, n (\%) & $48(10.7)$ & $36(100)$ \\
\hline Profession & $\mathrm{n}=449$ & $\mathrm{n}=36$ \\
\hline Physician, n (\%) & $134(29.8)$ & 8 (22.2) \\
\hline Nurse, n (\%) & $156(34.7)$ & $19(52.8)$ \\
\hline Assistant nurse, n (\%) & $38(8.5)$ & - \\
\hline $\begin{array}{l}\text { Psychotherapist/social } \\
\text { worker, n (\%) }\end{array}$ & $30(6.7)$ & - \\
\hline Administrative $\neq, n(\%)$ & $40(8.9)$ & - \\
\hline Other§, n (\%) & $51(11.4)$ & $9(25.0)$ \\
\hline PCC size & $n=406$ & $\mathrm{n}=36$ \\
\hline <24 employees, n (\%) & $104(25.6)$ & $15(41.7)$ \\
\hline$\geq 24$ employees, n (\%) & $302(74.4)$ & $21(58.3)$ \\
\hline $\begin{array}{l}\text { PCCs' geographical } \\
\text { locations }\end{array}$ & $n=406$ & $\mathrm{n}=36$ \\
\hline City, n (\%) & 127 (31.3) & $11(30.5)$ \\
\hline Urban, n (\%) & 195 (48) & $15(41.7)$ \\
\hline Rural, n (\%) & $84(20.7)$ & $10(27.8)$ \\
\hline
\end{tabular}

*Physician, nurse, assistant nurse, psychologist, social worker, physiotherapist, rehabilitation coordinator, chiropodist or occupational therapist.

†Director, medical secretary, receptionist, biomedical analyst, economist, team leader or human resources.

$\ddagger$ Medical secretary or receptionist.

§Physiotherapist, coordinator of rehabilitation, chiropodist, occupational therapist, biomedical analyst, economist, caretaker or human resources.

ПCity location: $>100000$ residents, urban location: town with $>200$ residents, rural location: area with villages with $<200$ resident. PCCs, primary care centres.

$74 \%$ neither disagreed nor agreed about their motivation to cooperate with the care manager. Nearly $48 \%$ neither agreed nor disagreed with the statement that the PCC had a formulated goal regarding the care manager function.

Only the statement 'there are opportunities to discuss how we should manage barriers that arise when working with the care manager' showed a lower frequency of agreement for smaller PCCs compared with larger PCCs ( $\geq 24$ employees), and 'I have sufficient knowledge about the care manager function' a lower frequency of agreement for rural compared with urban and city PCCs. About $9 \%$ of the clinicians were not at all familiar with the care manager's assignments. These respondents did answer 'no opinion' to the other items of the questionnaire in $70 \%-95 \%$ of the cases, and most of them were administrative staff rather than care providers (see table 2).

\section{Clinicians' perceptions of factors facilitating or hindering the cooperation with the care manager}

The results showed that $40 \%$ of the respondents prioritised working with the care manager (facilitator). Fortynine per cent of the respondents perceived that the assignment of the care manager corresponded to the aims of the PCC (facilitator), $42 \%$ perceived that they had support from colleagues and $51 \%$ perceived support from their directors in collaborating with the care manager (facilitators). Forty-nine per cent of the respondents did not perceive any conflict with existing routines (barrier), and $41 \%$ did not perceive any unclear division of responsibilities between the respondents as a clinician and the care manager (barrier).

Most respondents (70\%) reported that they were used to working with new methods and only $11 \%$ perceived that it was difficult to make use of the care management, while $48 \%$ completely or partly disagreed with this statement. There were only minor differences concerning the statement 'I have received information about the care manager's function', where urban personnel had lowest frequency of agreement, and concerning 'I have a low level of knowledge about the care manager function' where city PCC personnel agreed least. For all other facilitating and hindering factors, there was agreement between PCCs size and rural-urban-city PCCs (see table 3).

PCC directors' perceptions of the care manager implementation The results showed that $57 \%$ of the PCC directors had reorganised the PCC in conjunction with the care manager implementation and $43 \%$ had not. This was more often the case in smaller than larger PCCs. Eighty-eight per cent considered that the development of the assignment of the care manager had been clearly designed. Eighty-two per cent stated that the county council had drafted written requirements for how to perform the implementation (see table 4 ).

\section{Qualitative results}

Thirty-six directors and 135 clinicians answered the openended questions. Their responses were short and concise, and as the responses did not differ in any essential way, the responses were analysed together (see table 5).

\section{Organisational changes}

\section{Resourceful caretaking}

The implementation of care managers had resulted in organisational changes at the PCCs, such as forming 
Table 2 Clinicians' level of agreement with statements related to the care manager implementation

\begin{tabular}{|c|c|c|c|c|c|c|c|}
\hline \multirow[b]{2}{*}{ CFIR-constructs } & \multirow[b]{2}{*}{$\mathbf{N}$} & \multirow{2}{*}{$\begin{array}{l}\begin{array}{l}\text { Completely/partly } \\
\text { disagree }\end{array} \\
\% \text { (n) }\end{array}$} & \multirow{2}{*}{$\begin{array}{l}\begin{array}{l}\text { Neither } \\
\text { agree nor } \\
\text { disagree }\end{array} \\
\%(n)\end{array}$} & \multirow{2}{*}{$\begin{array}{l}\text { Almost/completely } \\
\text { agree } \\
\% \text { (n) }\end{array}$} & \multirow{2}{*}{$\begin{array}{l}\text { Missings } \\
\% \text { (n) }\end{array}$} & \multirow{2}{*}{$\begin{array}{l}\text { P value* }^{*} \\
\text { PCC size }\end{array}$} & \multirow{2}{*}{$\begin{array}{l}\text { P value } \\
\begin{array}{l}\text { Rural, urban, } \\
\text { city }\end{array}\end{array}$} \\
\hline & & & & & & & \\
\hline \multicolumn{8}{|l|}{ Inner setting } \\
\hline \multicolumn{8}{|l|}{ Networks and communications } \\
\hline $\begin{array}{l}\text { There are opportunities to } \\
\text { discuss how we should manage } \\
\text { barriers that arise when working } \\
\text { with the care manager }\end{array}$ & 447 & $33(146)$ & $37(167)$ & $30(134)$ & $0(0)$ & $\begin{array}{l}<0.01<24 \\
\text { employees } \dagger\end{array}$ & NS \\
\hline \multicolumn{8}{|l|}{ Self-efficacy } \\
\hline $\begin{array}{l}\text { I am able to influence how } \\
\text { we cooperate with the care } \\
\text { manager at my PCC }\end{array}$ & 446 & $21(92)$ & $15(67)$ & $35(157)$ & $29(130)$ & NS & NS \\
\hline
\end{tabular}

*Statistical differences between PCCs in relation to PCC size ( $<24$ employees or $\geq 24$ employees) and geographical location (rural, urban, city) are indicated by $p$ for size and $p$ for geographical location.

†In the $p$ columns where statistically significant differences are indicated $(p<0.01)$ information has been added concerning which group belongs to lowest frequency of 'almost /completely agree'.

CFIR, Consolidated Framework for Implementation Research; NS, Non significant; PCCs, primary care centres.

psychosocial teams that gave opportunities to raise important issues for the mental health patient group and that increased the interest in patients with CMD. These changes had resulted in a clear organisation and improved utilisation of the PCC's resources.

We now have a clear organization regarding how to manage the treatment of patients with common mental disorder. (Director)

On the other hand, when there was good access to resources in the psychosocial area, the perception was that a care manager did not add anything further to the care.

The size of the PCC could facilitate or hinder the possibility to get in contact with the care manager. Among smaller PCCs, the contact was facilitated by patients having easy access to the care manager, and the implementation of the care manager, with its designated time and structured approach together with frequent and active contacts with the patient, led to revised routines with early assessment resulting in improved patient flow.

The clinicians perceived that the care manager was as supportive when it came to medical follow-ups of patients with CMD. As a consequence, the clinicians perceived themselves to be less isolated when giving mental healthcare.
It's not so psychologically burdensome when I know the patient has a contact with another person regarding his mental mood. (Clinician)

\section{Barriers}

\section{The art of creating enough time in a tight work situation}

It takes time for a new role such as the care manger to get incorporated at the PCCs, which made it difficult for the clinicians to have sufficient knowledge about the care manager function.

New routines are difficult to implement. It takes some time for the function to get incorporated. (Director)

There were also concerns raised about the lack of time for cooperation, an overall high workload or the care manager being absent from the PCC. This could lead to the care manager function not being used as intended and could result in difficulties when introducing a new care manager into the PCC team or loss of benefit for clinicians and patients.

We have a deficit in clinicians at the PCC. If much else "floats", this is not a priority. The care manager quit last autumn and there is no successor. (Clinician)

Directors and clinicians experienced that when many other demands or tasks were put on the PCC at the 
Table 3 Clinicians' level of agreement with facilitating and hindering factors

\begin{tabular}{|c|c|c|c|c|c|c|c|}
\hline \multirow[b]{2}{*}{ CFIR-constructs } & \multirow[b]{2}{*}{$\mathbf{N}$} & \multirow{2}{*}{$\begin{array}{l}\begin{array}{l}\text { Completely/partly } \\
\text { disagree }\end{array} \\
\%(n)\end{array}$} & \multirow{2}{*}{$\begin{array}{l}\begin{array}{l}\text { Neither agree } \\
\text { nor disagree }\end{array} \\
\% \text { (n) }\end{array}$} & \multirow{2}{*}{$\begin{array}{l}\text { Almost/completely } \\
\text { agree } \\
\%(n)\end{array}$} & \multirow{2}{*}{$\begin{array}{l}\text { Missings } \\
\% \text { (n) }\end{array}$} & \multirow{2}{*}{$\begin{array}{l}\text { P value* } \\
\text { PCC size }\end{array}$} & \multirow{2}{*}{$\begin{array}{l}\text { P value* } \\
\begin{array}{l}\text { Rural, urban, } \\
\text { city }\end{array}\end{array}$} \\
\hline & & & & & & & \\
\hline \multicolumn{8}{|l|}{ Outer setting } \\
\hline \multicolumn{8}{|l|}{ External policies and incentives } \\
\hline $\begin{array}{l}\text { Working with care coordination } \\
\text { has low priority }\end{array}$ & 445 & $44(197)$ & $12(51)$ & $10(45)$ & $34(153)$ & NS & NS \\
\hline \multicolumn{8}{|l|}{ Implementation climate } \\
\hline $\begin{array}{l}\text { The goal of the PCC is not in } \\
\text { agreement with the goals of the } \\
\text { care manager }\end{array}$ & 445 & 44 (194) & $7(31)$ & $7(32)$ & $42(188)$ & NS & NS \\
\hline \multicolumn{8}{|l|}{ Readiness for implementation } \\
\hline $\begin{array}{l}\text { I have received information } \\
\text { about the care manager's } \\
\text { function }\end{array}$ & 445 & $16(69)$ & $14(61)$ & $60(267)$ & $10(48)$ & NS & $\begin{array}{l}<0.01 \\
\text { urban† }\end{array}$ \\
\hline $\begin{array}{l}\text { I have a low level of knowledge } \\
\text { about the care manager } \\
\text { function }\end{array}$ & 444 & $52(231)$ & $13(56)$ & $24(106)$ & $11(51)$ & NS & $<0.01$ city $\dagger$ \\
\hline
\end{tabular}

*Statistical differences between PCCs in relation to size ( $<24$ employees or $\geq 24$ employees) and geographical location (rural, urban, city) are indicated by $p$ for size and $p$ for geographical location.

†In the $p$ columns where statistically significant differences are indicated $(p<0.01)$, information has been added concerning which group that belongs to lowest frequency of 'almost /completely agree'

CFIR, Consolidated Framework for Implementation Research; NS, Non significant; PCCs, primary care centres.

same time, it affected the ability to implement the care manager function.

It is easily mixed up with other efforts concerning mental health. That is, many parallel similar tasks are ongoing. (Director)

\section{Facilitators}

\section{The soft values}

Some believed that in order to make the collaborative care with a care manager work, it was important to have a good collaborative climate among the director and the clinicians at the PCC and to have a positive attitude to new challenges.

All clinicians are interested in developing the role of the care manager together. The clinicians are not "afraid" of new and extended responsibilities.

(Director)

The personal characteristics of the care manager were valued as important, such as having a great interest in mental health as well as a willingness to interact with the other clinicians at the PCC.

The care manager is flexible, very helpful to both colleagues and patients, provides feedback after visits and conversations, and helps with the juggling of problems. (Clinician)

\section{Structured roll-out}

The majority of the directors stated that the financial compensation was crucial for allocating resources for the implementation of the care manager.

The directors also experienced that their participation in the education of the care manager on 1 out of 3 days of the care manager course was an important factor for the implementation.

Some of the directors and clinicians believed that the support from the implementation team was valuable and contributed to making the care manager function clearer and possible to develop.

Much support leads to a more thorough development of the function = it becomes clearer at the PCC.

(Director)

\section{DISCUSSION}

\section{Summary of main results}

The results concerning the study's first aim revealed that most of the clinicians perceived that they had support from colleagues and directors, and that there were routines for the work in collaborative care with care manager at their PCC. Almost all PCC directors were positive to the implementation and rated their clinicians' attitudes to the implementation as positive in most of the 
Table 4 PCC directors' level of agreement with statements related to the care manager implementation

\section{CFIR-constructs}

\begin{tabular}{|c|c|c|c|c|}
\hline \multicolumn{5}{|l|}{ Inner setting } \\
\hline \multirow[t]{2}{*}{ Readiness for implementation } & \multirow[t]{2}{*}{$\mathbf{N}$} & Yes & No & Missing \\
\hline & & $\%$ (n) & $\%$ (n) & $\%$ (n) \\
\hline \multirow[t]{2}{*}{ Implementation climate } & \multirow[t]{2}{*}{$\mathbf{N}$} & $\begin{array}{l}\text { Very negative/ } \\
\text { somewhat negative }\end{array}$ & $\begin{array}{l}\text { Very } \\
\text { positive/somewhat } \\
\text { positive }\end{array}$ & Missing \\
\hline & & $\%$ (n) & $\%$ (n) & $\%$ (n) \\
\hline $\begin{array}{l}\text { What are the attitudes of your colleagues and } \\
\text { coworkers towards the development of the care } \\
\text { manager function? }\end{array}$ & 36 & $3(1)$ & $75(27)$ & $22(8)$ \\
\hline \multirow[t]{2}{*}{$\begin{array}{l}\text { Knowledge and beliefs of the intervention and self- } \\
\text { efficacy }\end{array}$} & \multirow[t]{2}{*}{$\mathbf{N}$} & $\begin{array}{l}\text { Very low priority/ } \\
\text { somewhat low } \\
\text { priority }\end{array}$ & $\begin{array}{l}\text { Very high } \\
\text { priority/somewhat } \\
\text { high priority }\end{array}$ & Missing \\
\hline & & $\%$ (n) & $\%$ (n) & $\%$ (n) \\
\hline $\begin{array}{l}\text { What priority do you think that working with the } \\
\text { development of the care manager function has in your } \\
\text { activities today? }\end{array}$ & 36 & $28(10)$ & $69(25)$ & $3(1)$ \\
\hline
\end{tabular}

${ }^{*}$ Most common further education of existing staff was the joint education for care managers and their directors.

CFIR, Consolidated Framework for Implementation Research; PCC, primary care centre.

cases, with a greater proportion of positive ratings found at small and urban PCCs than at large, city or rural PCCs. Most directors had reorganised their PCCs as well and had educated staff. The factors highlighted with regard to successful implementation were the overall positive attitudes of clinicians who would be interacting with the care manager, and that their work with the care manager was supported by guidelines, education and support from colleagues and directors. These findings are well inline with previous studies. ${ }^{10-12} 21-24$

Concerning the study's second aim, the results showed that support from colleagues and the director, the clinician's cooperative skills and positive attitudes and perceiving that the care manager's function was well inline with the PCC's 'aim' and existing routines facilitated the implementation. High workload, high load of requirements and demands from the healthcare organisation and high turnover or shortage of staff formed barriers to both implementation of and collaboration within the collaborative care organisation with care managers.

\section{Findings in relation to other studies}

Our findings are in broad agreement with the findings of a review with regard to the barriers and facilitators identified. ${ }^{10}$ The authors of the review concluded that implementation requires 'buy in' from commissioners to ensure that financial barriers are removed, and that allowing sufficient training for staff is essential both at the planning stage and in the long term. ${ }^{10}$

Inline with our findings, this review as well as other studies highlight the importance of specially trained staff with the right training and support employed for this role. Soft values such as cooperative skills and positive attitudes towards the challenges of the care manager and the other staff are also mentioned as important facilitators. ${ }^{102}$ The care manager being on-site at the PCC is seen as an asset facilitating collaboration with the other staff. ${ }^{1021}$ In the present study, no respondent highlighted the well-known benefit of a standardised systematic clinical pathway, which the care manager intervention represents. ${ }^{8} 1012$

Table 5 Categories and subcategories developed from questions with open-ended answers

\begin{tabular}{llll}
\hline Category & Organisational changes & Barriers & Facilitators \\
\hline Subcategory & Resourceful caretaking & The art of creating enough time in a tight work situation & Structured roll-out \\
Subcategory & & & The soft values \\
\hline
\end{tabular}


The present findings of time and workload being critical factors when implementing collaborative care agree with other studies. ${ }^{22} 24$

\section{Strengths and limitations}

The strengths of this questionnaire survey are several. First, a major strength is that at baseline, collaborative care organisation with a care manager was implemented at 83 (out of 200) PCCs, thus providing the opportunity to apply a strategic sampling of PCCs with regard to geographical location, funding and PCC size. Second, a strength is that the items in the questionnaire directed towards clinicians were assessed with regards to reliability (test-retest). ${ }^{20}$ Third, the timing was chosen such that the introduction and implementation of a care manager at the PCC had been going on for at least a year, and the organisational change had had time to be adapted to the competence of the clinicians and organisation of the individual PCC. Fourth, the participation rate was outstanding for the PCC directors. Even though the answers from the open-ended questions were concise, the additional information facilitated the exploration of important research questions concerning implementation as well as captured real-world perceptions important for clinicians and directors. This gave a multifaceted description of the implementation process. Fifth, this is one of the few reports on implementation of a care manager for depression treatment in primary care, where the collaborative care development is generated within the primary care context and within the PCC, and where the care manager is a part of the ordinary clinician staff and part of the ordinary PCC team. ${ }^{33}$

One limitation of the study is that the response rate among clinicians was $56 \%$, which might be considered as marginally acceptable. However, there was also a large amount of internally missing data. Bearing these two aspects in mind, the results should be interpreted with caution. Further, two statements in the questionnaire to clinicians refer to patients with depression and anxiety. These statements should have been interpreted as patients with depression and symptoms of anxiety as a part of the depression and not as patients with anxiety syndrome. This might have been misunderstood by the respondents. Another limitation is that the results can only partly be generalised to international primary care contexts, as the Swedish primary care organisation is different from many other countries. Swedish PCCs most often have several different competencies, including specialised GP and nurses, counsellors, psychotherapists, physiotherapists and administrators. A typical Swedish PCC contains at least 3-5 GPs, 7-10 nurses, 2 counsellors/psychotherapists and serves a population around 10 000.

No patients were included in the present study; however, patients' experiences were studied and are presented in another publication. ${ }^{17}$

\section{CONCLUSIONS}

In a large-scale implementation of collaborative care with a care manager, our findings regarding clinicians' and directors' perceptions are important aspects to take into account. Facilitators and barriers of the implementation, such as time, information, soft values and positive attitudes, financial structure, as well as organisational changes made, were identified and are well in line with previous international studies. Our study confirms that the care manager puts collaborative care into practice even in the PCC.

The present study indicates that the implementation of a care manager for depression and CMD at PCCs, now present in around 100 Swedish PCCs, has been partly successful, but that there still remains important aspects needing consideration concerning information sharing, knowledge about care management and financial, organisational, administrative and professional structures. To reach sustainability, all of these factors must receive continuous attention, both at the PCC level and at the regional management level.

Acknowledgements The authors are grateful to the participating PCCs and their staff and directors. The authors also grateful for the support and cooperation with Region Västra Götaland, the region's implementation team, and Research and Development Primary Health Care.

Contributors PA recruited participants and collected the data. PA and $\mathrm{AH}$ analysed the data and wrote the majority of the paper. IS, CB, EBB and ELP designed the study and wrote the paper. IS, CB, ELP and EBB were the trial managers, supervised the data collection and interpreted the data. All authors have extensive training and experience in conducting cross-sectional research. All authors read and approved the final version of the manuscript.

Funding This work was supported by the Västra Götaland Region of Sweden, Grant number: VGFOUREG-856661. The study sponsor had no role in the collection, analysis, interpretation of data or writing of the report or the decision to submit the article for publication. All authors were independent from the funder.

Competing interests None declared.

Patient consent for publication Not required.

Ethics approval The study was approved by the Regional ethical review board in Gothenburg (diary number: 2016 / T403-15 ad 903-13). The participants were, in the invitation email, informed that the participation was voluntary and that the participants could at any time withdraw their consent to participation without giving any reason. Participants consented to participation by submitting the questionnaire.

Provenance and peer review Not commissioned; externally peer reviewed.

Data availability statement Data are available upon reasonable request. Inquiries for data access should be sent to University of Gothenburg, Sahlgrenska Academy, Institute of Medicine, School of Public Health and Community Medicine/ Primary Health Care, Box 454, 40530 Gothenburg, Sweden, generalpractice@ allmed.gu.se or the author Cecilia Björkelund cecilia.bjorkelund@gu.se, who will then contact the Swedish Ethical Review Authority for permission to openly share the data.

Open access This is an open access article distributed in accordance with the Creative Commons Attribution Non Commercial (CC BY-NC 4.0) license, which permits others to distribute, remix, adapt, build upon this work noncommercially, and license their derivative works on different terms, provided the original work is properly cited, appropriate credit is given, any changes made indicated, and the use is non-commercial. See: http://creativecommons.org/ licenses/by-nc/4.0/.

\section{ORCID iDs}

Pia Augustsson http://orcid.org/0000-0002-4698-4151

Cecilia Björkelund http://orcid.org/0000-0003-4083-7342

Elisabeth Björk Brämberg http://orcid.org/0000-0002-0204-5144 


\section{REFERENCES}

1 Gunn J, Diggens J, Hegarty K, et al. A systematic review of complex system interventions designed to increase recovery from depression in primary care. BMC Health Serv Res 2006;6:88.

2 Archer J, Bower P, Gilbody S, et al. Collaborative care for depression and anxiety problems. Cochrane Database Syst Rev 2012;10:CD006525

3 Behandling av depressionssjukdomar. En systematisk litteraturöversikt. [Treatment of depression. A systematic review]. Stockholm: Swedish Council on Technology Assessment in Health Care, 2004

4 WHO. Who methods and data sources for global burden of disease estimates 2000-2011. Geneva; 2013. www.who.int/healthinfo/ statistics/GlobalDALYmethods.pdf2013

5 Kessler RC, Demler O, Frank RG, et al. Prevalence and treatment of mental disorders, 1990 to 2003. N Engl J Med 2005;352:2515-23.

6 Nieuwenhuijsen $\mathrm{K}$, Faber B, Verbeek JH, et al. Interventions to improve return to work in depressed people. Cochrane Database Syst Rev 2014;12:CD006237.

7 Van den Broeck K, Remmen R, Vanmeerbeek M, et al. Collaborative care regarding major depressed patients: a review of guidelines and current practices. J Affect Disord 2016;200:189-203.

8 Björkelund C, Svenningsson I, Hange D, et al. Clinical effectiveness of care managers in collaborative care for patients with depression in Swedish primary health care: a pragmatic cluster randomized controlled trial. BMC Fam Pract 2018;19:28.

9 Holst A, Ginter A, Björkelund C, et al. Cost-Effectiveness of a care manager collaborative care programme for patients with depression in primary care: economic evaluation of a pragmatic randomised controlled study. BMJ Open 2018;8:e024741.

10 Wood E, Ohlsen S, Ricketts T. What are the barriers and facilitators to implementing collaborative care for depression? A systematic review. J Affect Disord 2017;214:26-43.

11 Richards DA, Bower P, Chew-Graham C, et al. Clinical effectiveness and cost-effectiveness of collaborative care for depression in UK primary care (CADET): a cluster randomised controlled trial. Health Technol Assess 2016;20:1-192.

12 Coventry P, Lovell K, Dickens C, et al. Integrated primary care for patients with mental and physical multimorbidity: cluster randomised controlled trial of collaborative care for patients with depression comorbid with diabetes or cardiovascular disease. BMJ 2015;350:h638.

13 Goodrich DE, Kilbourne AM, Nord KM, et al. Mental health collaborative care and its role in primary care settings. Curr Psychiatry Rep 2013;15:383.

14 Implementeringsstöd för psykiatrisk evidens i primärvården. En systematisk litteraturöversikt. [Implementation support for the psychiatric evidence in primary care. A systematic review] Stockholm: Swedish Council on Health Technology Assessment, 2012.

15 Walshe K. Understanding what works--and why--in quality improvement: the need for theory-driven evaluation. Int J Qual Health Care 2007;19:57-9.

16 Moore GF, Audrey S, Barker M, et al. Process evaluation of complex interventions: medical Research Council guidance. BMJ 2015;350:h1258.
17 Udo C, Svenningsson I, Björkelund C, et al. An interview study of the care manager function-Opening the door to continuity of care for patients with depression in primary care. Nurs Open 2019;6:974-82.

18 Svenningsson I, Petersson E-L, Udo C, et al. Process evaluation of a cluster randomised intervention in Swedish primary care: using care managers in collaborative care to improve care quality for patients with depression. BMC Fam Pract 2019;20:108.

19 Svenningsson I, Udo C, Westman J, et al. Creating a safety net for patients with depression in primary care; a qualitative study of care managers' experiences. Scand J Prim Health Care 2018;36:355-62.

20 Björk Brämberg E, Jensen I, Kwak L. Nationwide implementation of a national policy for evidence-based rehabilitation with focus on facilitating return to work: a survey of perceived use, facilitators, and barriers. Disabil Rehabil 2020;42:1-9.

21 Whitebird RR, Solberg LI, Jaeckels NA, et al. Effective implementation of collaborative care for depression: what is needed? Am J Manag Care 2014;20:699-707.

22 Overbeck G, Davidsen AS, Kousgaard MB. Enablers and barriers to implementing collaborative care for anxiety and depression: a systematic qualitative review. Implement Sci 2016;11:165.

$23 \mathrm{Holm}$ AL, Severinsson E. Chronic care model for the management of depression: synthesis of barriers to, and facilitators of, success. Int $J$ Ment Health Nurs 2012;21:513-23.

24 Møller MCR, Mygind A, Bro F. Who needs collaborative care treatment? A qualitative study exploring attitudes towards and experiences with mental healthcare among general practitioners and care managers. BMC Fam Pract 2018;19:78.

25 Brämberg EB, Klinga C, Jensen I, et al. Implementation of evidencebased rehabilitation for non-specific back pain and common mental health problems: a process evaluation of a nationwide initiative. BMC Health Serv Res 2015;15:79.

26 Hellman T, Jensen I, Bergström G, et al. Essential features influencing collaboration in team-based non-specific back pain rehabilitation: findings from a mixed methods study. $J$ Interprof Care 2016;30:309-15.

27 Kirk MA, Kelley C, Yankey N, et al. A systematic review of the use of the consolidated framework for implementation research. Implement Sci 2015;11:72.

28 Damschroder LJ, Aron DC, Keith RE, et al. Fostering implementation of health services research findings into practice: a consolidated framework for advancing implementation science. Implement Sci 2009;4:50.

29 Svenska Akademiens ordböcker Stockholm: Svenska Akademien, 2017. Available: https://svenska.se/ [Accessed 25 Feb 2018].

30 Dahiru T. P - value, a true test of statistical significance? A cautionary note. Ann Ib Postgrad Med 2008;6:21-6.

31 Graneheim UH, Lindgren B-M, Lundman B. Methodological challenges in qualitative content analysis: a discussion paper. Nurse Educ Today 2017;56:29-34.

32 Graneheim UH, Lundman B. Qualitative content analysis in nursing research: concepts, procedures and measures to achieve trustworthiness. Nurse Educ Today 2004;24:105-12.

33 Taylor EF, Machta RM, Meyers DS, et al. Enhancing the primary care team to provide redesigned care: the roles of practice facilitators and care managers. Ann Fam Med 2013;11:80-3. 